\title{
O uso da ferramenta criativa de analogia na criação de uma coleção de moda com estampas do tipo engineered print
}

\section{The use of analogy as a creative tool in the development of a fashion collection with engineered prints}

\author{
Paola Taianne Pallu \\ Graduada em Design de Moda pela Faculdade de Tecnologia SENAI Curitiba - paolataianne@gmail.com \\ Daniele Lugli \\ Doutoranda em Art, Design and Architecture pela Monash University (Melbourne, Australia) - danilugli@gmail.com
}

\begin{abstract}
Resumo
O presente artigo apresenta o desenvolvimento de uma coleção para o público feminino com estampas do tipo engineered print, por meio da ferramenta criativa de analogia. Tal ferramenta se resume na análise de diferentes referências buscando encontrar possíveis conexões e, a partir disso, uma nova inspiração. A aplicação da mesma na criação das estampas permitiu uma leitura diferenciada dos relatórios de tendências, que, amplamente disseminados, acabam por padronizar os temas presentes nas coleções de moda comerciais. Tal diferencial, bem como o uso da técnica engineering print para estampas únicas, agregaram maior exclusividade à coleção desenvolvida.
\end{abstract}

Palavras-chave: Estamparia. Desenvolvimento de coleção - moda. Engineered print.

\begin{abstract}
This paper presents the development of a women's garment collection with engineered prints, through the creative tool of analogy. This tool consists in the analysis of different references in order to find possible connections and, from that, a new inspiration. The use of the tool in the creative process of the prints allowed a different reading of the trend reports, which, widely disseminated, end up standardizing the themes presented in commercial fashion collections. This differential, as well as the use of the engineered technique for unique prints, added exclusivity to the collection.

Keywords: Pattern design. Collection development - fashion. Engineered print.
\end{abstract}

Recebido em: 15/05/2017

Aceito em: 17/09/2018 


\section{INTRODUÇÃO}

De acordo com Laschuk e Rüthschilling (2013), ser um designer de superfície é lidar com a arte de criar. Assim, torna-se relevante a investigação de métodos inovadores para a criação e desenvolvimento de estampas, um mercado cada vez mais promissor, mas, ao mesmo tempo, saturado com as mesmas ideias e referências. Uma técnica cada vez mais utilizada no design de superfícies, com o intuito de gerar um produto mais exclusivo, é o engineered print, que consiste no desenvolvimento de estampas diretamente sobre o molde da peça.

No design, existem muitas técnicas de criação que contribuem para a geração de ideias inovadoras. Dentre elas, encontra-se a ferramenta de analogia, que se resume na análise de diferentes objetos, buscando encontrar possíveis conexões entre eles. Segundo Aznar (2011), existem analogias lógicas e intuitivas e, ambas, podem ser exploradas de maneira metódica por meio do intelecto.

Dessa forma, o presente estudo apresenta a aplicação da ferramenta de analogia na criação de uma coleção feminina a partir de informações de um relatório de tendências. O processo criativo conduziu a uma temática relacionada às tendências, porém não explícita no relatório. Como resultado, foram gerados produtos únicos que, por meio do engineered print, exploraram as interações entre estampa e corpo.

\section{DESIGN DE SUPERFÍCIE E ESTAMPARIA}

Sendo uma ramificação do design de superfície, a estamparia têxtil consiste no conjunto de técnicas e processos de impressão para a transferência de imagens e desenhos para superfície de tecidos (LASCHUK; RÜTHSCHILLING, 2013). De acordo com Vieira (2014) compreende-se o termo como o processo de pintar ou imprimir sobre o tecido, através de corantes, de modo que se formem figuras ou desenhos.

Assim, estamparia é a arte de decorar um tecido, seja por estampas do tipo rapport, também chamada de estampa corrida, ou estampa localizada. Tal arte não é novidade para a moda, entretanto, a estamparia passa por um momento de revitalização e reinvenção, contando com novas técnicas e tecnologias que permitem à indústria da moda também reinventar-se.

O faturamento do setor têxtil e de confecções em 2017 cresceu 5,6\% em comparação ao ano anterior, atingindo $\mathrm{R} \$ 144$ bilhões, de acordo com a Associação Brasileira da Indústria Têxtil da 
Confeç̧ão (ABIT, 2017). Esse dado aponta um momento de recuperação da indústria após alguns anos de queda em seu faturamento. A respeito disso, Alfredo Bonduki, presidente do Sinditextil, afirma que "a crise vai passar em algum momento. Temos que continuar a olhar para frente e absorver as novas tendências de produtos e de gestão" (Portal Nacional de Seguros, 2016).

Sobre as tendências de produto, observa-se uma propensão tecnológica voltada para o corpo e como o vestuário relaciona-se com o corpo que veste. Aplicações tecnológicas em tecidos já são uma realidade que proporcionam a criação inovadora de materiais, e a moda permite que estas novidades tecnológicas sejam praticamente realizadas, associando a tecnologia e a estética (FUJITA; JORENTE, 2015).

De acordo Petry e Abreu (2011), percebe-se que o mercado de design de estamparia têxtil passou por um crescimento nos últimos anos e ainda está em fase de desenvolvimento. Tal evolução se deve a consciência das empresas de que a estamparia pode ser um diferencial na manifestação da identidade das marcas em suas coleções de moda. Assim, a indústria busca técnicas e tecnologias no design de superfícies que permitam o desenvolvimento de produtos do vestuário de fato diferenciados - dentre eles, encontram-se os métodos de estamparia digital e a técnica de engineering print.

Figura 1 - Molde de um top cropped, com estampa engineered print.
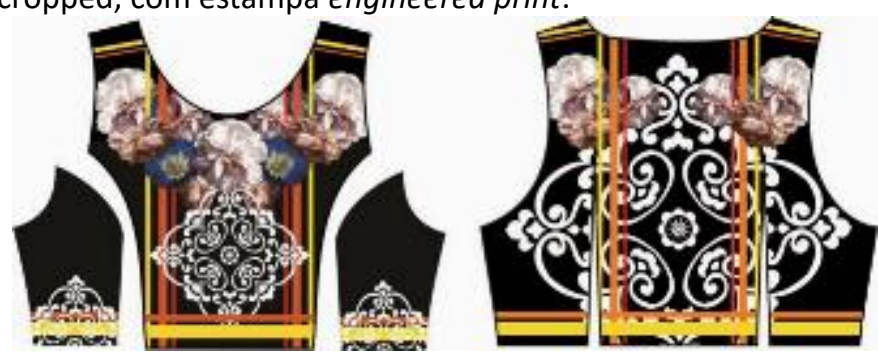

Fonte: elaborado pelas autoras.

Engineered prints, segundo Laschuk e Rüthschilling (2013), são estampas desenvolvidas com localização pré-definida, posteriormente aplicadas em um têxtil diretamente no molde da peça. Este processo de estamparia estimula a redução de desperdício, visto que a estampa será impressa nos moldes de forma estabelecida, e contribui para o desenvolvimento de estampas exclusivas, sem delimitação em relação a tamanho e cores. A técnica de engineering print se destaca na estamparia por não utilizar um módulo de repetição e, em muitos casos, é utilizada na 
criação de desenhos que proporcionam a continuidade da estampa através das diversas partes da modelagem, mesmo com recorte e costura da peça, como exemplifica a figura 1.

O engineered print, só pode ser realizado digitalmente, portanto, pertence à área da estamparia digital, que possibilita ao designer têxtil lidar essencialmente com o computador e posteriormente passar para o tecido, sem a necessidade de desenhar propriamente no papel. Assim, torna-se viável elaborar imagens com alta resolução e imprimir sem a necessidade da utilização de inúmeras telas, como ocorre na serigrafia (UDALE, 2009).

\section{FERRAMENTAS DE CRIATIVIDADE}

A criatividade é algo imprescindível para o designer. Conforme Ostrower (2010, p.9) "Criar é, sobretudo, produzir. É ser capaz de dar uma forma a algo inédito". A maneira que se estimula a mente a pensar de forma criativa é um desafio ao longo da história de qualquer profissional. Segundo a autora, as associações provêm de áreas inconscientes da mente e elas compõem o significado do mundo criativo. São ligações, previsões da origem de semelhanças, reflexões individuais e íntimas apoiadas em experiências precedentes.

Sobre isso, Alencar (2001, p.15) afirma que:

Ao longo da história humana a criatividade tem sido um assunto de extrema relevância, cujas implicações transcendem do bem-estar do indivíduo para toda sociedade. $\mathrm{Na}$ antiguidade a criatividade era vista como parte da natureza humana, considerado como um dom divino, um "estado místico de receptividade a algum tipo de mensagem proveniente de entidades divinas".

São muitas as técnicas e ferramentas utilizadas no design para estimular e facilitar o processo criativo. Nesse estudo, explora-se a ferramenta de criatividade chamada analogia que, conforme Aznar (2011), indica uma relação de semelhança entre coisas diferentes. A chave do conceito está em detectar atributos semelhantes em coisas diferentes, e uni-las com o objetivo de executar um processo criativo. Existem vários tipos de analogias: algumas são racionais, lógicas, científicas; outras, unicamente intuitivas, subjetivas.

A sua aplicação consiste primeiramente em um exercício que trabalha com a área emocional. Define-se um tema e depois se busca relações de semelhança, por meio de palavras ou imagens. A atividade pode ser executada individualmente ou em grupo. De acordo com Aznar 
(2011), é possível seguir diferentes procedimentos ao realizar a analogia, conforme descrito no quadro 1:

Quadro 1 - Procedimento analógico e suas descrições.

\begin{tabular}{|l|l|}
\hline \multicolumn{1}{|c|}{ Procedimento Analógico } & \multicolumn{1}{c|}{ Descrição } \\
\hline A) Analogia direta & Questionamento: o conceito me faz pensar no que? \\
\hline B) Analogia temporal & Questionamento: Como era no passado? Como será no futuro? \\
\hline C) Analogia simbólica ou metafórica & Relação instantânea, resposta poética \\
\hline D) Analogia Gráfica & Tradução do conceito em formas e cores \\
\hline F) Parábola & Descrição de um conceito em forma de história \\
\hline G) Metáfora & Tradução em imagens globais \\
\hline
\end{tabular}

Fonte: Aznar (2011, p. 100-101).

O autor ainda exemplifica a aplicação de tais procedimentos a partir da palavra e sentimento "Amor" (p. 101):
A) Amor faz pensar em lealdade, em eterno, família, companheirismo e dor.
B) No passado o amor era algo imaturo e instável, no futuro será algo sólido e seguro.
C) O amor cego imortaliza a alma incrédula e arde como fogo.
D) Vermelho e uma forma circular.
E) Segundo a mitologia grega, Afrodite era a Deusa do amor, da fertilidade.
F) Figura 2 .

Figura 2 - Tradução em imagens globais.

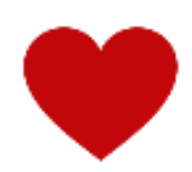

Fonte: Adaptado de Aznar (2011).

Conforme o quadro 1, existem muitas possibilidades de analogia, inclusive, a mistura de procedimentos é algo permitido. Independente do procedimento analógico, esta ferramenta ajuda a traduzir o conceito e a referência de imagens abstratas em inspirações reais. A condição de associação neste procedimento requer muito da imaginação, instigando um movimento espontâneo no subconsciente. Finalmente, como a analogia é uma conexão própria e única de quem está utilizando-a, para cada pessoa o resultado de analogia poderá ser diferente. 


\section{TENDÊNCIAS COMO REFERÊNCIA CRIATIVA INICIAL}

Para o desenvolvimento criativo das estampas proposto nesse estudo, foi necessário um referencial inicial como ponto de partida para a ferramenta criativa de analogia. Para isso, foi realizada uma pesquisa de macrotendências para a temporada de inverno 2017. Segundo Caldas (2004) macrotendências, também chamadas de tendências de fundo, são correntes influentes socioculturais que interferem, em tese, no consumo, na cultura, nas sociedades, por grandes temporadas. Essas manifestações são tangíveis, informações que estão para acontecer futuramente e abrangem diversas áreas apresentando uma grande proporção.

Analisando-se as macrotendências para 2017, o portal Use fashion (2016), apresenta uma temática chamada "Viagens poéticas". Ela é baseada no filósofo Alain de Botton e seu livro "A arte de viajar":

\footnotetext{
Se nossas vidas são dominadas pela busca da felicidade, talvez poucas atividades revelem tanto a respeito da dinâmica desse anseio - com toda a sua empolgação e seus paradoxos - quanto o ato de viajar. Ainda que de maneira desarticulada, ele expressa um entendimento de como a vida poderia ser fora das limitações do trabalho e da luta pela sobrevivência.
}

Figura 3 - Viagem poética, moodboards, palavras.

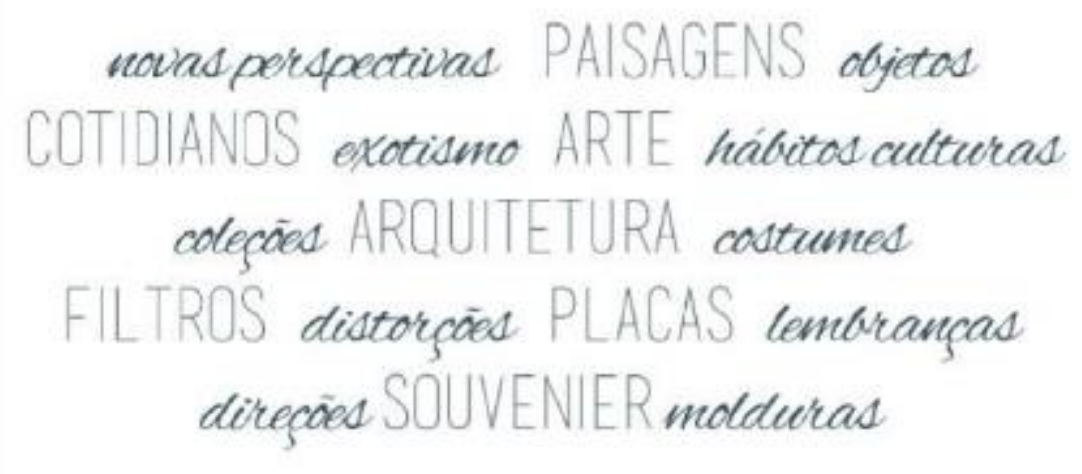

Fonte: USE FASHION (2016).

Ainda de acordo com o portal, o sentimento do viajar não se apresenta apenas quando se chega ao destino final, mas também ao longo do aprendizado que ocorre em todo o percurso da viagem. À medida que se passa pelos lugares, a câmera se torna uma extensão do corpo, guardando cada mínimo detalhe. O melhor na viagem está nas pequenas coisas que acontecem ali. Dessa forma, as palavras-chaves desta macrotendência estão representadas na figura 3. 
Já a figura 4 representa os painéis de inspiração que remetem visualmente à macrotendência. Os painéis imagéticos são importantes nessa leitura porque uma macrotendência traz referências visuais e conceituais múltiplas. Segundo Ostrower (2010), a imagem referencial liga-se a um fenômeno de percepção que ainda é pouco elucidado, mas cuja importância é indiscutível, tanto para as ordenações como para o sentido que as formas têm na interpretação individual.

Figura 4 - Viagem poética, moodboards, palavras.

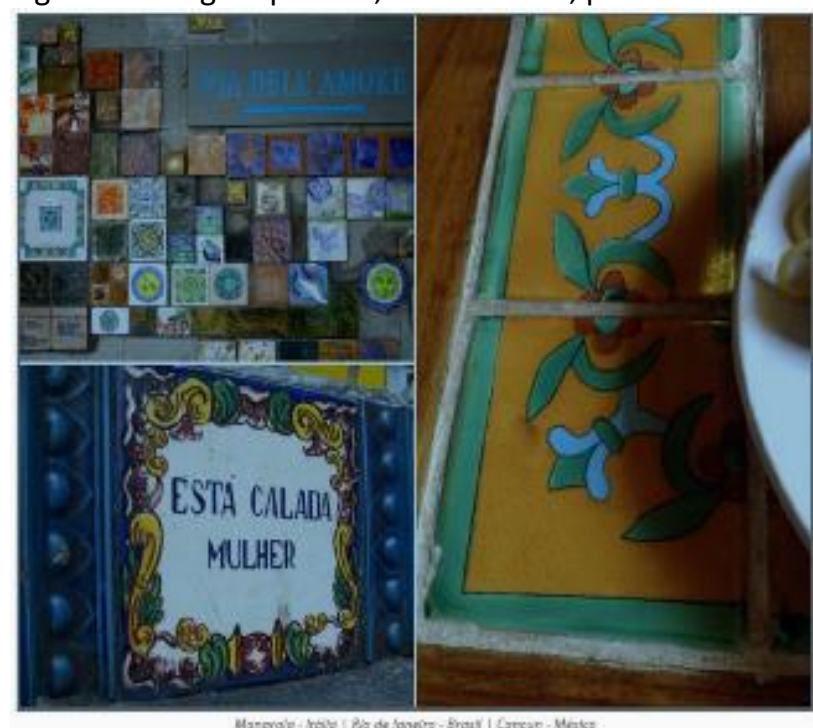

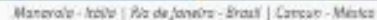

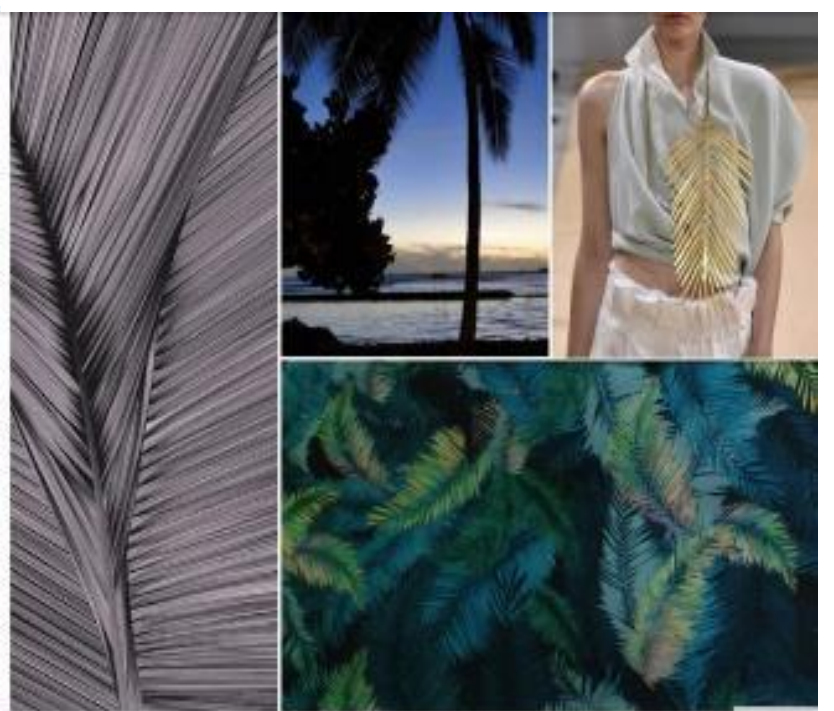

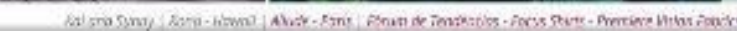

Fonte: USE FASHION (2016).

Percebe-se que a temática "Viagens Poéticas" é um referencial complexo, que tem como foco as inspirações, algo subjetivo. Dessa forma, a ferramenta de analogia pode contribuir para a formalização do pensamento e a geração de alternativas de fato diferenciadas.

\section{PROCESSO CRIATIVO}

A analogia é uma técnica criativa de assimilação entre duas ou mais ideias divergentes, que tem algo em comum. Junto a essa técnica, utilizou-se o mapa mental, também conhecido como pensamento radiante que, para Lupton (2013) é tipo de pesquisa mental que parte de um termo ou ideia central, permitindo mapear rapidamente imagens e propostas associadas. No processo criativo é possível utilizar a analogia direta, a simbólica ou metafórica e a gráfica. 
O processo criativo consistiu-se primeiramente em um exercício que trabalhou com a área emocional. Definiu-se como tema a macrotendência "Viagem Poética", do portal Use Fashion, e foram impressos os painéis da macrotendência em lâminas, colocadas sobre uma mesa. A partir daí, analisaram-se as imagens que tinham algo em comum, identificando determinadas figuras que se repetiam, as quais foram agrupadas e classificadas em três conjuntos: arcos metálicos, azulejos e placas.

O processo foi iniciado colocando-se a palavra principal no topo da folha. Em seguida, criou-se uma rede de associações por meio de cores diferenciadas. As palavras de associações foram relacionadas subconscientemente, incentivando o lado criativo e emocional da mente, com resultado apresentado nas figuras 5, 6 e 7 .

Figura 5 - Analogias a partir de "arcos metalizados".

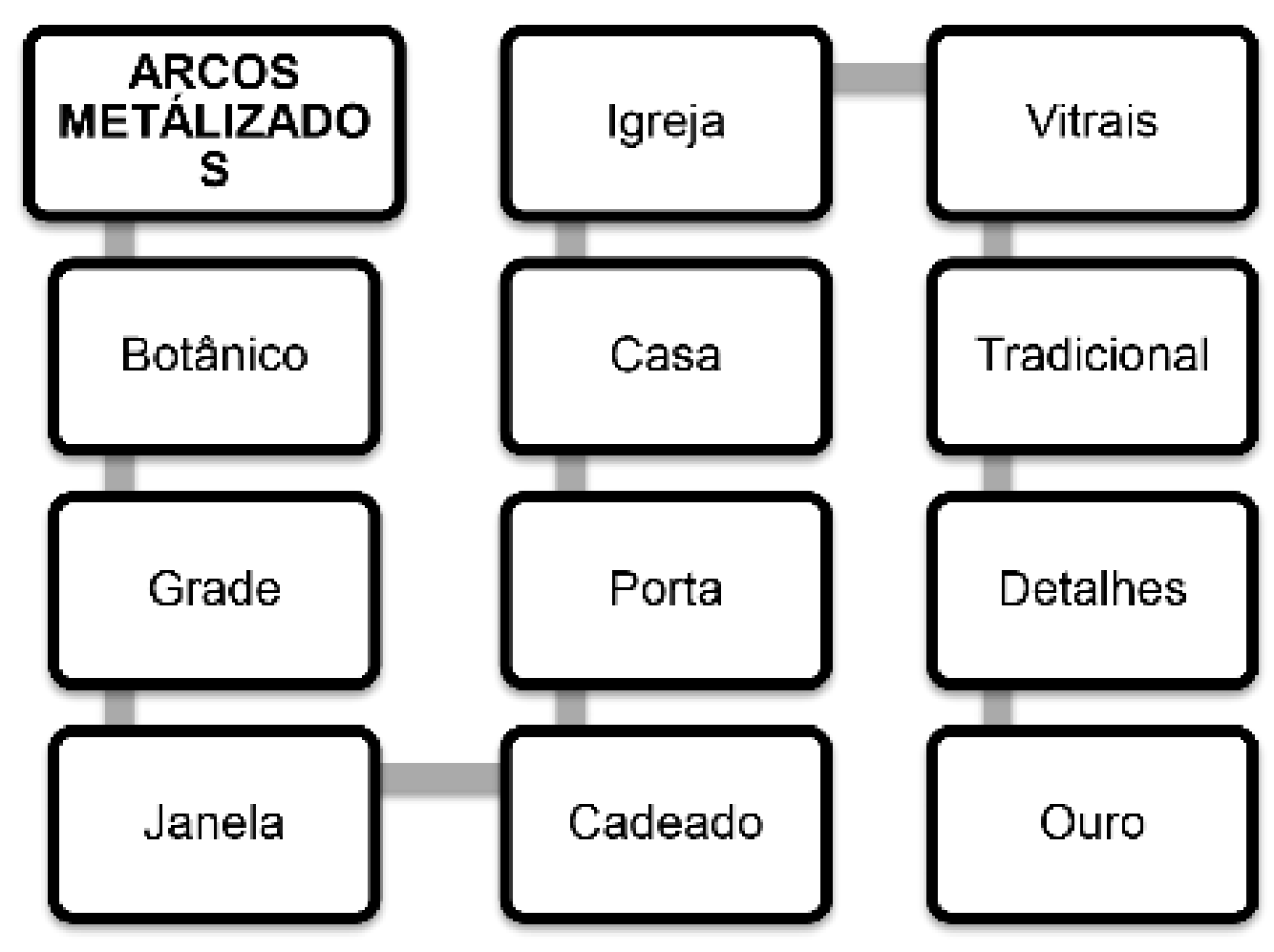

Fonte: elaborado pelas autoras (2016).

Figura 6 - Analogias a partir de "azulejos". 


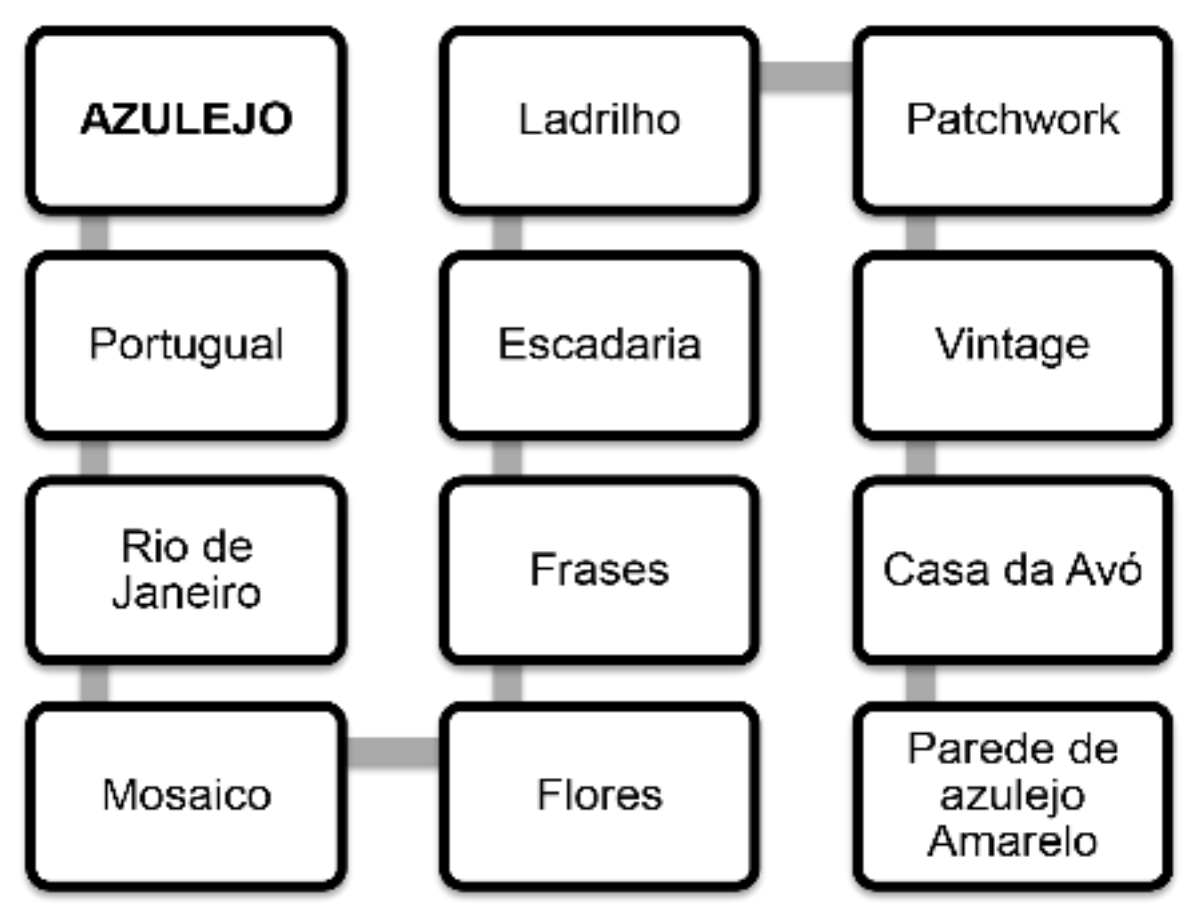

Fonte: elaborado pelas autoras (2016).

Figura 7 - Analogias a partir de "placa".

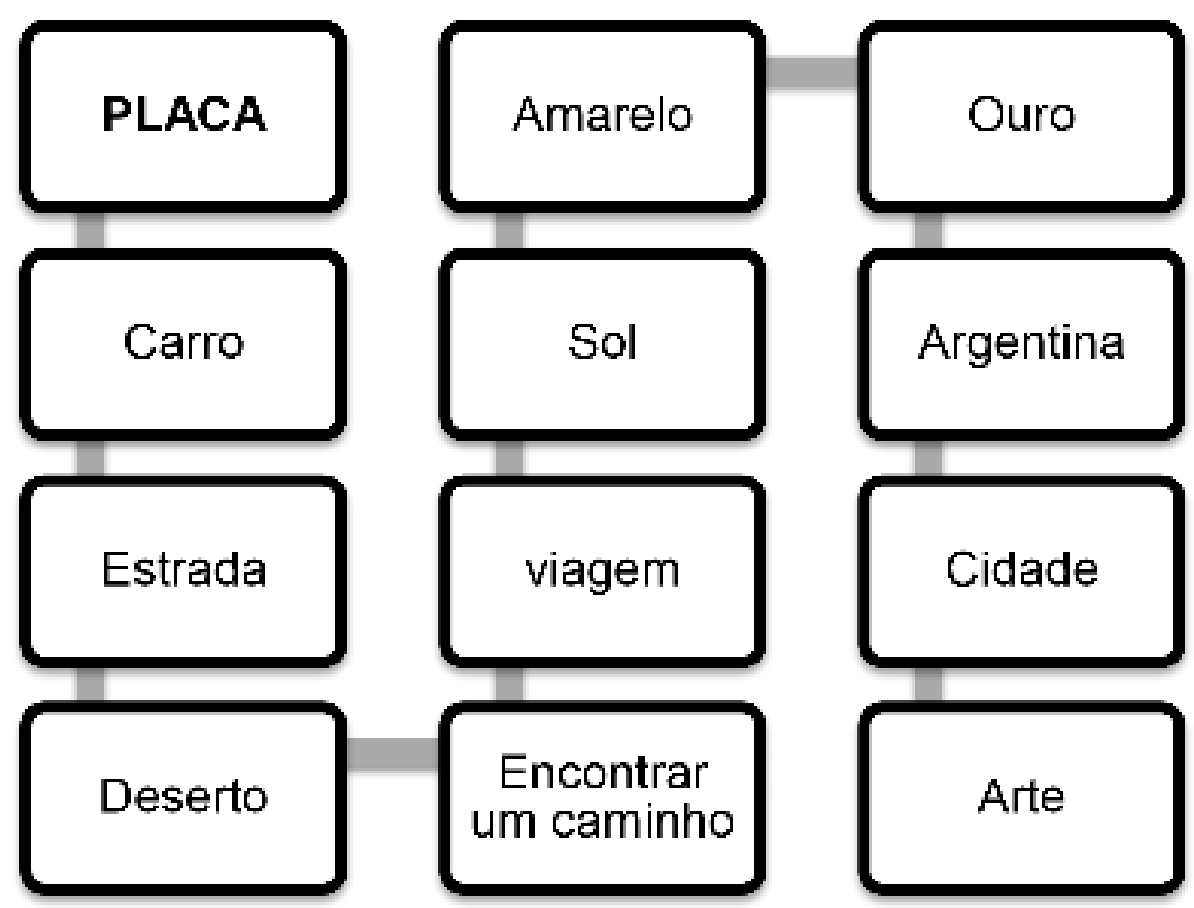

Fonte: elaborado pelas autoras (2016). 
Ao finalizar os mapas de analogia, foi possível observar que as palavras que remetiam ao ouro e ao amarelo se apresentaram com maior frequência. A partir dessa ideia, foi realizado mais uma vez um processo de analogia, explorando o repertório da criadora. Surge assim, a lembrança uma arte típica de Buenos Aires, capital da Argentina: o Fileteado.

\subsection{FILETEADO PORTEÑO}

Na Argentina, mais especificamente em Buenos Aires, surgiu no final do século XIX o Fileteado, uma prática artística de desenho e pintura, que tem como principal característica as linhas em espirais, a simetria, o uso das cores vivas e fortes, efeito de luz e sombra criando perspectiva. Os temas que se apresentam com frequência são estilizações de folhas, cornucópias, bandeirolas, animais, flores entre outros como apresenta a figura 8. A principal tipografia utilizada nesta arte é chamada de esgróstica, uma variação da fonte gótica, podendo variar junto com a cursiva (GUERRA, 2012).

Figura 8 - Filete porteño.

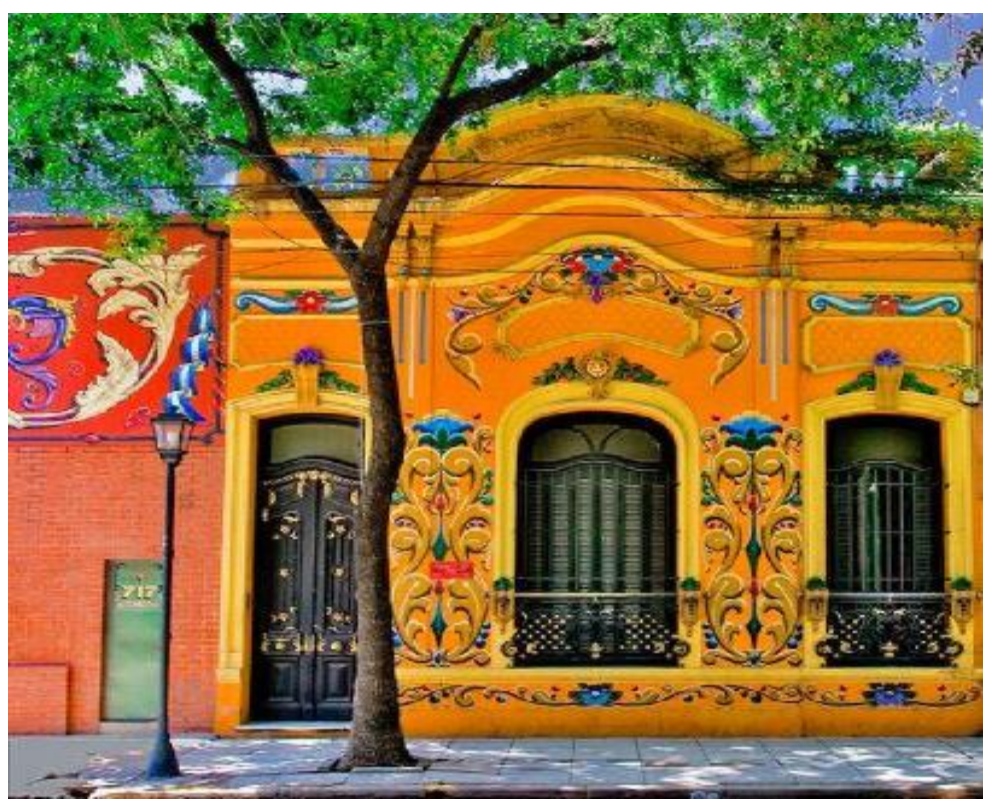

Fonte: Bevilaqua (2007).

Por volta de 1800 , essa prática da pintura era utilizada como um simples ornamento, para decorar carroças de tração animal que carregavam alimentos. Ao longo do tempo, se tornou uma arte típica da cidade de Buenos Aires. Na Argentina, os fileateadores geralmente eram imigrantes 
espanhóis e italianos. Como eram de origem humilde, a arte que eles produziam era relacionada a sentimentos e desejos, que remetiam a saudades do lugar que tinham nascido. O fileteado tem uma ligação com o tango, justamente por nascerem no subúrbio de Buenos Aires (GUERRA, 2012).

Enquanto inspiração, o tema apresenta muitas cores e detalhes, capazes de tornar uma peça de moda única. Dessa forma, a cartela de cores e os grafismos foram baseados nessas pinturas, exigindo uma extensa pesquisa de imagens de referência para se chegar ao resultado final, detalhado a seguir.

\section{RESULTADO}

Primeiramente foram esboçadas as peças, em forma de croqui, para a definição de shapes e uma ideia geral do tipo de elemento usado e seu posicionamento. Procurou-se utilizar modelos simples, sem muitos recortes ou recursos de modelagem, para que se evidenciasse a estamparia. Depois disso, a criação das estampas foi feita de maneira totalmente digital, sobre os moldes digitalizados e utilizando os elementos vetoriais desenhados a partir da inspiração, conforme exemplificado na figura 9.

Figura 9 - Exemplo de croqui e estampa desenvolvida digitalmente.

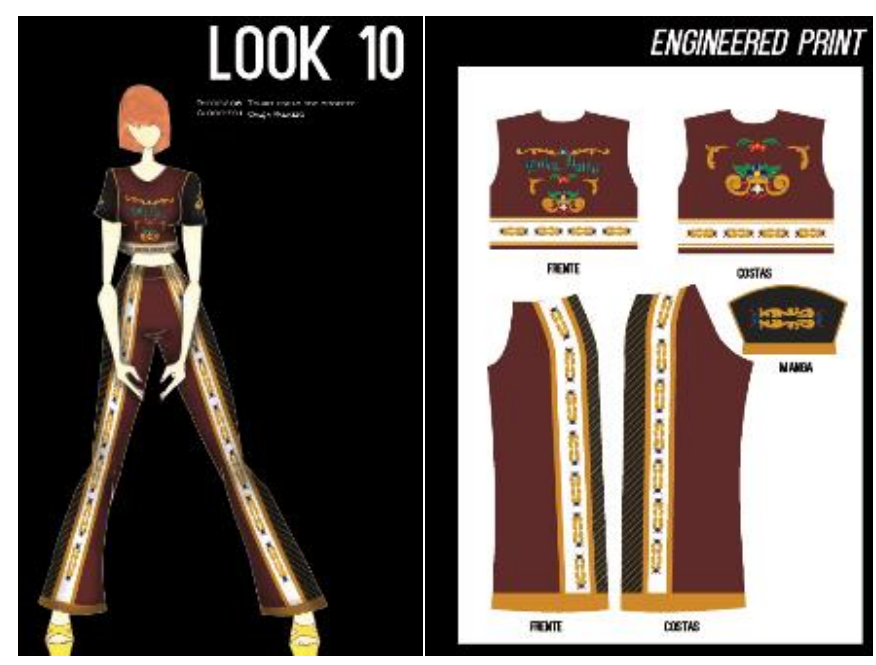

Fonte: Elaborado pelas autoras (2016).

Foram desenvolvidos ao todo 15 looks. Os tecidos selecionados para confecção foram o Two-way e a Helanca, ambos de composição poliéster com elastano, que permitem a estamparia por sublimação, processo mais acessível que a estamparia digital. As figuras 10, 11 e 12 apresentam 
O uso da ferramenta criativa de analogia na criação de uma coleção de moda com estampas do tipo engineered print

Paola Taianne Pallu, Daniele Lugli

algumas das peças - primeiramente cortadas, evidenciando as estampas desenvolvidas sobre o molde, e o resultado das mesmas após a confecção.

Figura 10 - Primeiro look desenvolvido.

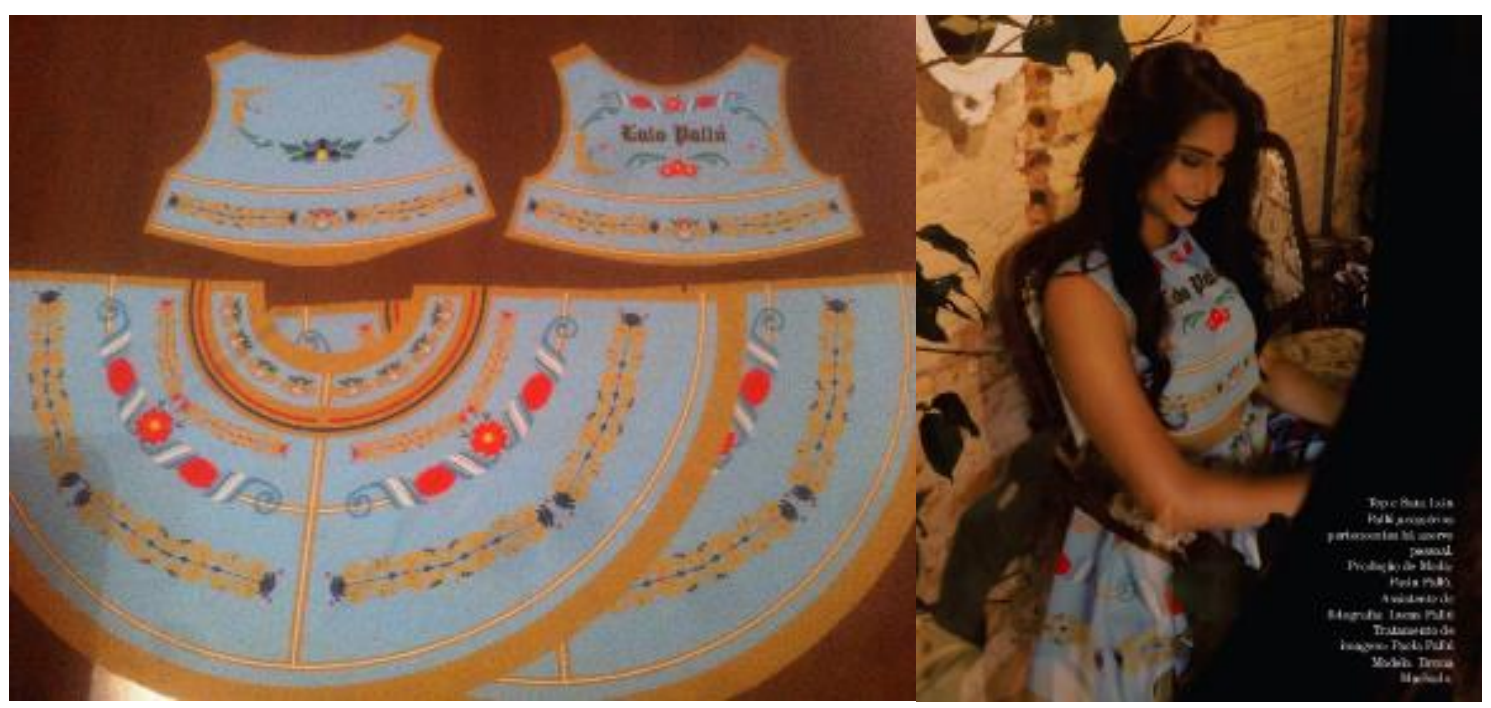

Fonte: Elaborado pelas autoras (2016).

Figura 11 - Segundo look desenvolvido.

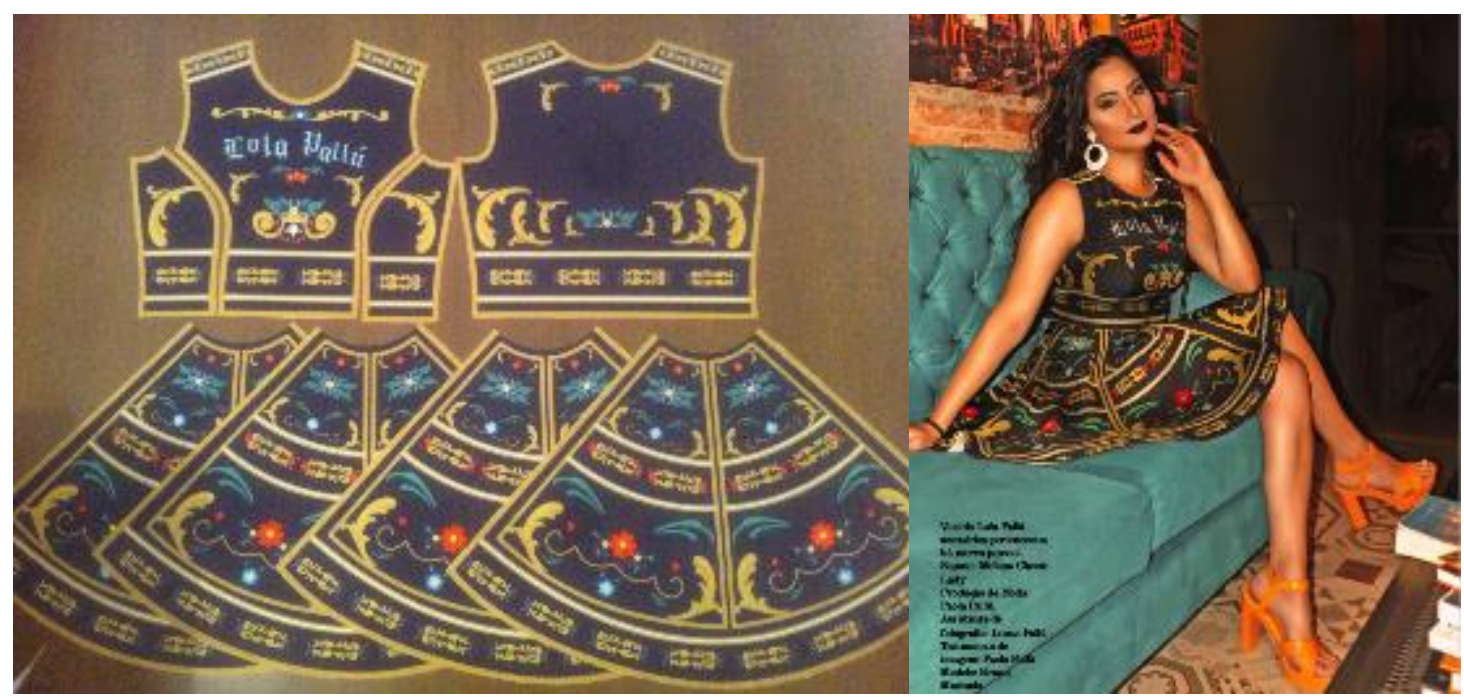

Fonte: Elaborado pelas autoras (2016). 
Figura 12 - Terceiro look desenvolvido.

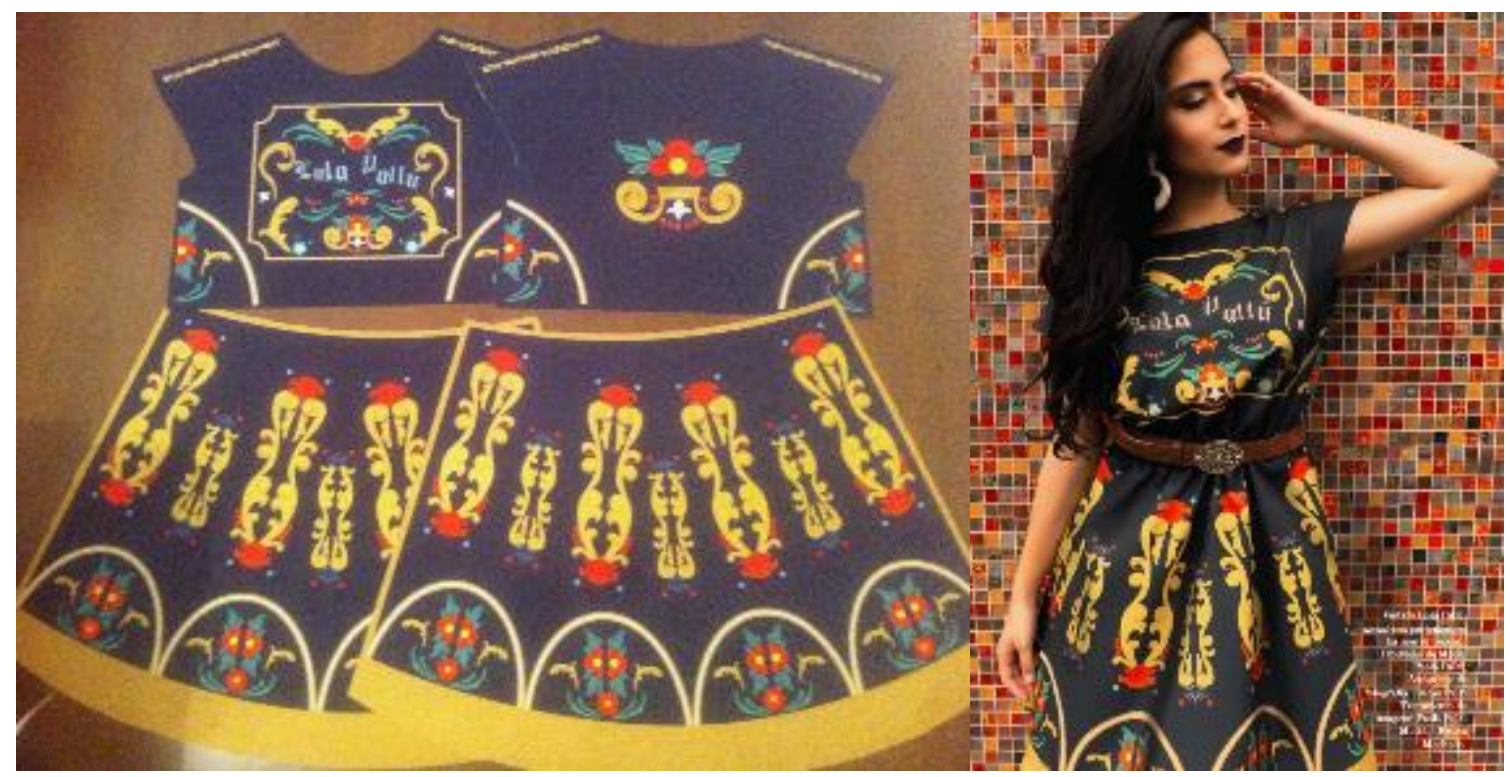

Fonte: Elaborado pelas autoras (2016).

Os elementos gráficos do fileteado foram arranjados de maneira única sobre cada um dos moldes, gerando peças com unidade de silhueta, porém distintas em seu resultado estético geral. As peças possuem aspecto comercial e acompanham a tendência estudada, porém, com uma abordagem diferenciada, que não estava explicitada no relatório inicial. Assim, conclui-se que a técnica de criatividade trouxe a diferenciação desejada, bem como a técnica de estamparia proporcionou o desenvolvimento de produtos únicos.

\section{CONSIDERAÇÕES FINAIS}

As ferramentas de criatividade auxiliam no processo criativo ao estimular a mente do criador a fazer associações e encontrar temas que estavam ocultos em seu subconsciente. Assim, o trabalho gerado torna-se não apenas rico em conteúdo e detalhes, mas também único ao agregar o repertório pessoal do designer. Essa pode ser uma importante estratégia de diferenciação em meio a uma indústria competitiva, porém muitas vezes uniformizada pela leitura simplista de tendências.

$\mathrm{Na}$ mesma busca por diferenciação, cresce o interesse da indústria pela técnica de engineering print, que permite a produção em pequena escala e com menor resíduo de peças com estampas exclusivas e que se adequam ao molde e ao próprio corpo da consumidora. Entretanto, a técnica exige do designer de estampas familiaridade com a modelagem plana, para que o 
posicionamento dos elementos e encaixe da estampa em recortes sejam realizados com precisão. Assim, o domínio da técnica torna-se uma oportunidade de diferencial também para profissionais que possuam tais competências.

O estudo prático realizado, embora limitado à aplicação da analogia e do engineering print, indica que a união entre ferramentas de criatividade e técnicas diferenciadas de estamparia pode apresentar resultados satisfatórios ao facilitar o processo criativo e a inovação no produto de moda. Assim, sugere-se que tal integração seja também verificada em outras áreas da criação, além da estamparia, ou a partir de diferentes ferramentas de criatividade.

\section{REFERÊNCIAS}

ABIT. Associação Brasileira da Indústria Têxtil e de Confecção. Setor têxtil e de confecção brasileiro fecha 2017 com crescimento. 2017. Disponível em: <http://www.abit.org.br/noticias/setor-textil-ede-confeccao-brasileiro-fecha-2017-com-crescimento>. Acesso em: 05 out. 2018.

ALENCAR, Eunice M. L. Soriano de. Pesquisadores que se destacam por sua produção criativa: hábitos de trabalho, escolha profissional, processo de criação e aspirações. In: ALENCAR, Eunice M. L. Soriano de. Criatividade e educação de superdotados. Petrópolis: Vozes, 2001.

AZNAR. Guy. Ideias: 100 técnicas de criatividade. São Paulo: Summus, 2011.

BEVILAQUA, Ricardo. 2007. Disponível em:

<https://www.flickr.com/photos/ricardobevilaqua/2269734699/>. Acesso em: 05 out. 2018.

CALDAS, Dario. Observatório de Sinais: teoria e prática da pesquisa de tendências. Rio de Janeiro: SENAC Rio, 2004.

FUJITA, Mayumi; JORENTE, Maria José Vicentini. A Indústria Têxtil no Brasil: uma perspectiva histórica e cultural. Moda Palavra, Florianópolis, v. 8, n. 15, p.153-174, jan./jul. 2015. Disponível em: <http://www.revistas.udesc.br/index.php/modapalavra/article/view/5893>. Acesso em: 05 out. 2018.

GUERRA, Julio César. El diseño gráfico argentino: el grabado aborigen y el filete porteño. Puentos de Partida. 2012. 74 f. Monografia - Curso de Licenciatura En Diseño Gráfico, Universidade Abierta Interamericana, Buenos Aires, 2012. Disponível em:

<http://imgbiblio.vaneduc.edu.ar/fulltext/files/TC109825.pdf>. Acesso em: 05 out. 2018.

LASCHUK, Tatiana; RUTHSCHILLING, Evelise Anicet. Engineered Print: o uso integrado da estamparia digital com a modelagem. In: COLOQUIO DE MODA, 9., 2013, Fortaleza. Anais... . Fortaleza: Ufc, 2013. p. 01 - 16. Disponível em:

<http://www.coloquiomoda.com.br/anais/Coloquio\%20de\%20Moda\%20-\%202013/ARTIGOS-DE- 
GT/Artigo-GT-Design-e-Processos-de-Producao-em-Moda/Engineered-Print-o-uso-integrado-daestamparia-digital-com-a-modelagem.pdf>. Acesso em: 08 out. 2018.

LUPTON, Ellen. Artes Gráficas: Design gráfico. São Paulo, G. Gilli, 2013.

OSTROWER, Faiga. Criatividade e processos de criação. Petrópolis: Vozes, 2010.

PETRY, Mila Cavalheiro; ABREU, Jorge Arantes Pinto de. Reflexões sobre o mercado de design para a estamparia têxtil no Rio de Janeiro. Redige: Revista de design, inovação e gestão estratégica, S.I., v. 2, n. 1, p.155-179, 2011. Disponível em:

<https://api.ning.com/files/8rDuWoKOzfKBpsqkhdVkzFUaLQt9DrZgi7E4LWGnuGXWGNGMLsQBaOy H94jGHhbeVdFn6yCRV1XMe62uhq2L8A7gy6fDrlQp/ReflexessobreoMercadodeDesignparaEstampa riaTxtilnoRiodeJaneiro154.pdf>. Acesso em: 08 out. 2018.

UDALE, Jenny. Fundamentos de design de moda: tecidos e moda. Porto Alegre:

Bookman, 2009.

USE FASHION. Viagens Poéticas. 2016. Disponível em:

<http://www.usefashion.com/Categorias/ConteudoPDF.aspx?IDConteudo=133312>.

Acesso em 05 set. 2018.

VIEIRA, Liliana Bellio. A estamparia têxtil contemporânea: produção, produtos e subjetividades. 2014. 226 f. Dissertação (Mestrado) - Curso de Têxtil e Moda, Pós-graduação em Têxtil e Moda, Universidade de São Paulo, São Paulo, 2014. Disponível em:

<http://www.teses.usp.br/teses/disponiveis/100/100133/tde-13082014-015615/pt-br.php>. Acesso em: 08 out. 2018. 